\title{
Sodium gating capacitance and the optimization of the squid giant axon for metabolic energy usage Patrick Crotty* and William B Levy
}

\author{
Address: Department of Neurological Surgery, University of Virginia Health System, Charlottesville, VA 22908, USA \\ Email: Patrick Crotty* - prc9m@virginia.edu \\ * Corresponding author
}

from Sixteenth Annual Computational Neuroscience Meeting: CNS*2007

Toronto, Canada. 7-12 July 2007

Published: 6 July 2007

BMC Neuroscience 2007, 8(Suppl 2):PI I4 doi:I0.I I86/I47I-2202-8-S2-PI I4

(c) 2007 Crotty and Levy; licensee BioMed Central Ltd.

\section{Background}

In previous work $[1,2]$, we observed that the ionic fluxes during an action potential (AP) in the squid giant axon can be divided into three functionally separate components. Of these, the component responsible for the depolarizing phase of the $\mathrm{AP}$, and hence its velocity, attains a minimum as a function of the ion channel densities and the axon diameter very near the experimental values of these parameters when the AP velocity is constrained to be at a single value. Since the ion channel fluxes are proportional to the metabolic energy consumption via the ATPase $\mathrm{Na}^{+} / \mathrm{K}^{+}$exchanger, this suggests that evolution, subject to an external constraint on AP velocity, has optimized ion channel densities and axon diameters for the energy associated with the velocity. The energy minimum is close to, although not identical with, a similar minimum in the total membrane capacitance. The total capacitance consists of the intrinsic membrane capacitance (about $0.88 \mu \mathrm{F} / \mathrm{cm}^{2}$ ) and a term proportional to the active $\mathrm{Na}^{+}$channel density (about $1 \mathrm{nF} / \mathrm{mS}$ of $\mathrm{Na}^{+}$), the so-called sodium "gating capacitance," which arises from movements of charged segments of the $\mathrm{Na}^{+}$protein during conformal changes. In the present work, we investigate and resolve the discrepancy in the locations of the energy and membrane capacitance minima.

\section{Methods}

The Hodgkin-Huxley squid giant axon model was simulated using NEURON and NMODL. The axon diameter and the ion channel densities were taken as two inde- pendent parameters, with the channel densities (consisting of voltage-gated $\mathrm{Na}^{+}$, voltage-gated $\mathrm{K}^{+}$, and nonspecific leak channels) varied by a common factor and parameterized by the maximum sodium conductance. Note that this also necessitated varying the sodium gating capacitance by this factor. Constraining the velocity to be at a single value, we determined how the shape and height of the action potential varied along the resulting isovelocity curve.

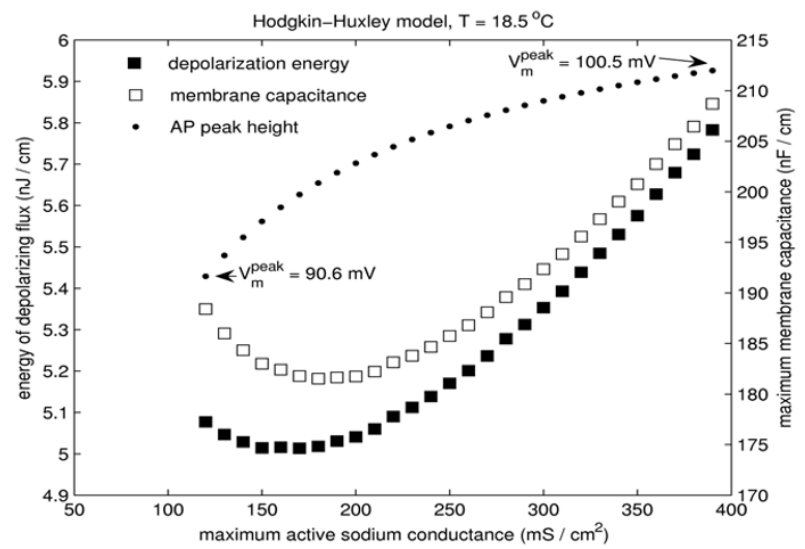

Figure I

Action potential peak height, depolarization energy and membrane capacitance as functions of sodium conductance. 


\section{Results}

Our results are summarized in Figure 1. All quantities are plotted on the $21.2 \mathrm{~m} / \mathrm{s}$ isovelocity curve in axon diameter-channel density phase space. The amount of charge per unit axial length on the membrane capacitor at the peak of the action potential is $q_{P}=c_{m} V_{m}$ peak, where $c_{m}$ is the total membrane capacitance per unit axial length. This charge is approximately equal to the total depolarizing charge crossing the membrane during the action potential, and hence is proportional to the metabolic energy. Since $V_{m}$ peak increases with the ion channel densities, values of $c_{m}$ further to the right are more heavily weighted in the product $c_{m} V_{m}$ peak. This causes the minimum in the charge and energy curves to be further to the left than in the $c_{m}$ curve alone.

\section{Conclusion}

The discrepancy between the locations of the energy and capacitance minima is resolved by considering the amount of charge placed on the membrane capacitor at the peak of the action potential. The AP peak-height rises with the ion channel densities, and therefore, the ion flux per unit membrane surface area across the membrane and the associated metabolic energy also increase. When this increase is taken into account, the location of the net charge minimum is at the same channel densities as the depolarizing energy minimum. This also illustrates that energy, rather than capacitance, is what evolution has minimized.

\section{References}

I. Crotty P, Sangrey T, Levy WB: Metabolic energy cost of action potential velocity. J Neurophysiol 2006, 96: |237-1246.

2. Levy WB, Sangrey T, Friesen WO, Crotty P: Reply to Jurisic and Bezanilla's letter to the editor. J Neurophys 2006, 96:960.
Publish with Biomed Central and every scientist can read your work free of charge

"BioMed Central will be the most significant development for disseminating the results of biomedical research in our lifetime. " Sir Paul Nurse, Cancer Research UK

Your research papers will be:

- available free of charge to the entire biomedical community

- peer reviewed and published immediately upon acceptance

- cited in PubMed and archived on PubMed Central

- yours - you keep the copyright

Submit your manuscript here:

http://www.biomedcentral.com/info/publishing_adv.asp 